Seminar Nasional Teknologi Informasi dan Kedirgantaraan (SENATIK)

Vol. II, 26 November 2016, ISSN: 2528-1666

\title{
ANALISA BEBAN KERJA DAN PENGEMBANGAN PERSAMAAN PREDIKSI KONSUMSI OKSIGEN PADA MAHASISWA PEKERJA INDUSTRI
(STUDI KASUS MAHASISWA TEKNIK INDUSTRI UNIVERSITAS RIAU KEPULAUAN)

\author{
Benedikta Anna Haulian Siboro1, Vera Methalina Afma² \\ Email : 1b.anna79@gmail.com, ${ }^{2}$ vera.afma@gmail.com \\ Program Studi Teknik Industri, Universitas Riau Kepulauan \\ Jl. Batu Aji Baru No. 99 Batam
}

\begin{abstract}
Majority of Industrial Engineering student at Riau Island Univeristy - Batam are workers who mostly worked in the electronics industry and shipbuilding with different kind of work.

In this research, the variables to be studied is work load which is done on whether the worker was within normal limits and develop VO2 consumption equation for each of these jobs by doing research using bike ergonometer and doing manual handling. The data obtained from recording of the heart rate, as well as student worker health data is later processed and searched the prediction equation using statistical methods such as the independence of the error test, test multicollinearity between independent variables and stepwise method

The results showed from 240 students, $80 \%$ of student work on the electronics manufacturing and the rest in other areas and does not work. It is also at submaximal measurements using Ergocycle bike show in the 8th minute decrease in heart rate and so is the removal of objects in a decrease in heart rate in the 10th minute and classified in extreme jobs. There was also a correlation between $\mathrm{VO} 2$ maximum height and heart rate in order to get the equation VO2 $=-0054+0015 \mathrm{High} \mathrm{HR}+8939$
\end{abstract}

Keywords : consumption VO2, bike Ergocycle, workload, type of work

\section{Pendahuluan}

Batam sebagai salah satu kota industri memiliki ratusan industri besar yang biasanya menjalankan usahanya di dalam kawasan-kawasan industri yang banyak berdiri di Batam. Kawasankawasan terbagi dalam beberapa kelompok yang menghasilkan produk sejenis seperti kawasan industri elektronik. Industri shipyard (galangan kapal). industri pipa/supporting part. industri rigging untuk pengeboran minyak. Masing-masing jenis industri besar ini memiliki beban kerja yang berbeda-beda. Untuk industri dengan jenis usaha elektronik sebagian besar karyawan adalah wanita. dan jenis usaha lainnya sebagian besar adalah pria.

Permasalahan muncul apabila beban pekerjaan (demand) dan kapasitas manusia (capacity) yang tidak seimbang. hal ini sangat beresiko besar terjadinya kelelahan kerja dan pada akhirnya akan terjadi kesalahan kerja atau kecelakaan kerja. Oleh karena itu dalam mendesain suatu pekerjaan dan peralatan kerja perlu memperhatikan demand dan capacity manusia. Cara agar beban pekerjaan tidak melebihi kapasitas kerja manusia adalah dengan mengetahui berat ringannya beban kerja dan mengukur aktivitas kerjanya. Salah satu pendekatan yang digunakan adalah dengan menggunakan indikator konsumsi oksigen (VO2).

Menurut Leyland dalam Sukawati [1] nilai VO2 merupakan gambaran aktivitas dari kemampuan paru-paru mengambil oksigen. kemampuan jantung memompa darah. kemampuan 
hemoglobin mendistribusikan oksigen. Kemampuan otot mendapatkan suplai oksigen dan kemampuan mitokondria serta enzim tubuh untuk menghasilkan energi sehingga pengukuran konsumsi oksigen ini dapat menggambarkan organ-organ tersebut dalam satu integritas.

\section{Metode Penelitian}

Lokasi penelitian dilakukan di Laboratorium Analisa Perancangan Kerja dan Ergonomi Teknik Industri Universitas Riau Kepulauan dengan objek penelitian ini adalah mahasiswa Teknik Industri yang mayoritas bekerja di industri elektronik dan galangan kapal. Obyek penelitian ini adalah mahasiswi (wanita) yang bekerja di elektronik dan galangan kapal. Berikut adalah diagram alir penelitian ini.

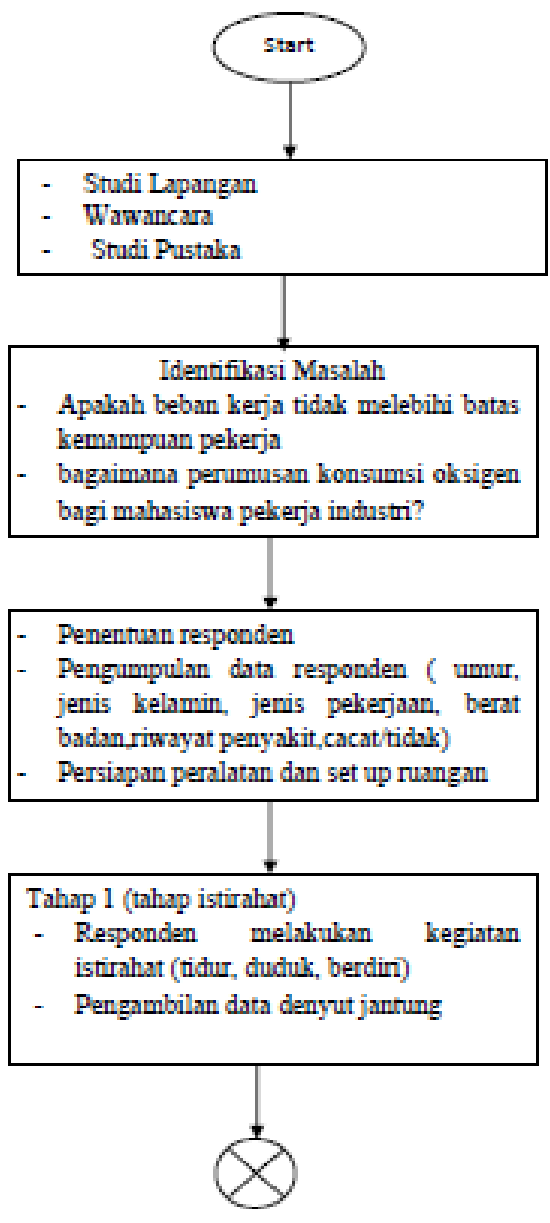

Gambar 1 Tahapan penelitian
Adapun variabel yang diamati dalam penelitian ini adalah :

a. Variabel Dependen. meliputi :

1. Beban kerja yang dilakukan oleh pekerja

2. Konsumsi VO2 max yang terkandung dalam tubuh pekerja

b. Variabel Independen meliputi: Umur, Jenis pekerjaan pekerja, Berat badan, Riwayat kesehatan dan Lamanya waktu kerja

Penelitian ini memfokuskan pada jenis-jenis pekerjaan yang dilakukan oleh mahasiswa pekerja yang akan mempengaruhi beban kerja dan konsumsi VO2 pekerja itu sendiri.

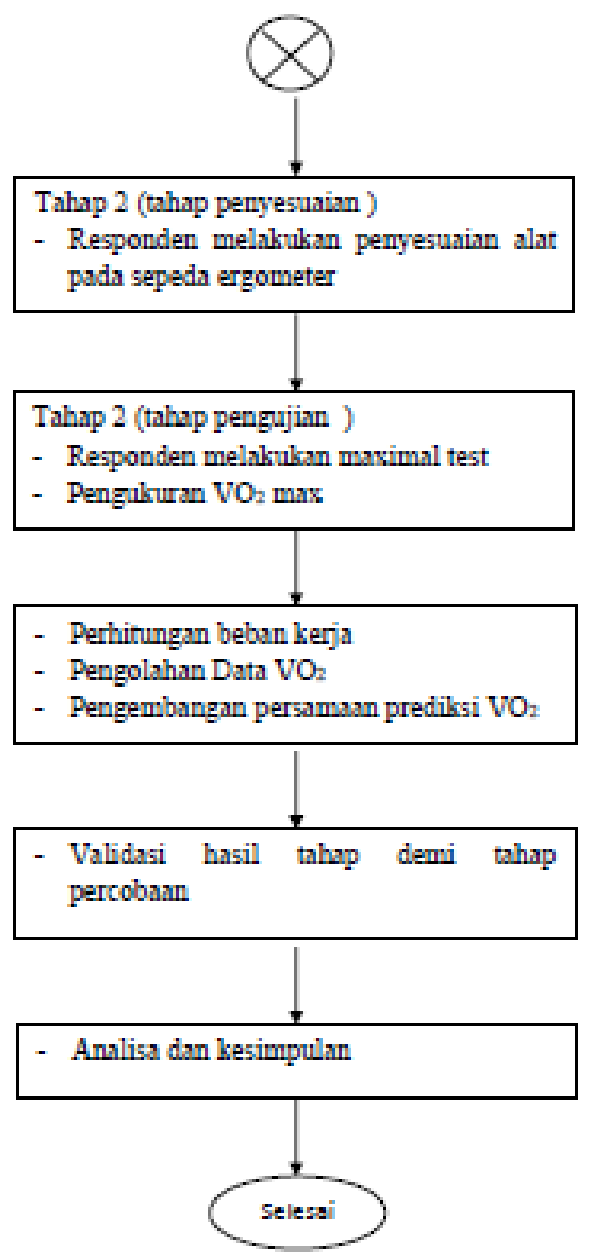

Gambar 2 penelitian (lanjutan) 


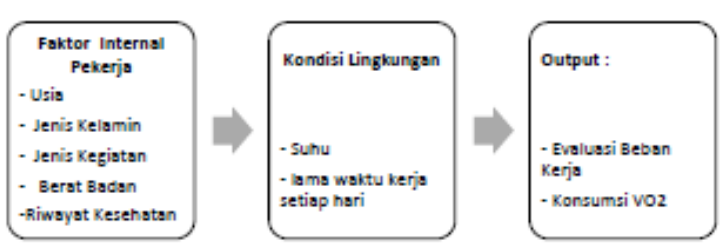

Gambar 3 Model Penelitian

\section{Produktivitas}

International Labour Organization (ILO) dalam Hasibuan [2] mengatakan bahwa secara lebih sederhana maksud dari produktivitas adalah perbandingan secara ilmu hitung antara jumlah yang dihasilkan dan jumlah setiap sumber yang dipergunakan selama produksi berlangsung. Sumber tersebut dapat berupa tanah, bahan baku pabrik, mesin dan tenaga kerja. Faktor sumber daya manusia ini merupakan elemen yang harus diperhatikan oleh perusahaan terutama bila mengingat bahwa era perdagangan bebas akan segera dimulai dimana iklim kompetisi yang dihadapi akan sangat berbeda.

Menurut Sinungan [3] terdapat dua kelompok syarat bagi produktivitas sumber daya agar SDM (sumber daya manusia) perorangan tinggi:

1. Kelompok pertama

a. Tingkat pendidikan dan keahlian

b. Jenis teknologi dan hasil produksi

c. Kondisi kerja

d. Kesehatan. kemampuan fisik dan mental

2. Kelompok kedua

a. Sikap mental (terhadap tugas). teman sejawat dan pengawas

b. Keaneka ragam tugas

c. Sistem insentif (sistem upah dan bonus)

d. Kepuasan kerja

Pada persyaratan kelompok 1 terkandung faktor kesehatan pekerja yang juga akan mempengaruhi kualitas dari produktivitas tersebut. Dalam hubungan antara kesehatan dan produktivitas kerja terdapat faktor-faktor yang mempengaruhinya antara lain:

a. Beban Kerja

Setiap pekerjaan merupakan beban bagi pelaku kerja. Beban kerja mencakup beban fisik ( mengangkat. memikul. dan lain-lain). Beban mental (tanggung jawab bawahan terhadap atasan). beban social b. Beban tambahan dari lingkungan kerja Beban tambahan ini mencakup lingkungan fisik kerja seperti kebisingan, suhu. tekanan udara. penerangan dan getaran

c. Kapasitas kerja

Kapasitas kerja seseorang dipengaruhi oleh keterampilan. Kesehatan jasmani dan rohani. keadaan kesehatan, tingkat gizi, jenis kelamin,umur, ukuran-ukuran tubuh.

Ketiga faktor di atas harus berada dalam keseimbangan yang serasi agar didapat derajat kesehatan yang optimal dan produktivitas yang tinggi.

\section{Ergonomi dan Fisiologi Kerja}

Untuk memudahkan pemahaman mengenai ergonomi. maka ruang lingkupnya terdiri atas beberapa bagian :

a. Ergonomi Fisik : berkaitan dengan anatomi tubuh manusia, antropometri, karakteristik fisiologi dan biomekanika yang berhubungan dengan aktifitas fisik

b. Ergonomi kognitif : berkaitan dengan mental manusia seperti persepsi, ingatan,reaksi sebagai hasil akibat dari interaksi manusia terhadap elemen didalamnya

c. Ergonomi organisasi berkaitan dengan optimasi sistem. struktur oganisasi dan proses

d. Ergonomi lingkungan yang berkaitan dengan pencahayaan, temperatur, kebisingan. dan getaran.

Beberapa metode didalam lingkungan kerja dipakai untuk menilai keergonomisan suatu lingkungan kerja antara lain :

a. Diagnosis dengan melakukan wawancara dan inspeksi terhadap kondisi lingkungan kerja

b. Treatment dilakukan dengan membuat perlakuan-perlakuan khusus dan melihat reaksi dari perlakuan yang dibuat

c. Follow up dengan melakukan evaluasi yang subyektif atau obyektif mengenai kenyamanan dan atau ketidaknyaman yang ditimbulkan seperti nyeri. kepala pusing,dan lain-lain.

Fisiologi kerja merupakan salah satu ilmu yang mempelajari bagaimana kinerja atau fungsi tubuh dan komponen-komponennya. Menurut Astrant dkk [4] tujuan dari fisiologi kerja adalah mempelajari 
kinerja seseorang dalam menyelesaikan pekerjaan tanpa mengalami kelelahan pada akhir hari kerja dan masih ada tenaga yang cukup agar pekerja dapat menikmati waktu luang akhir pekannya.

\section{Kapasitas Kerja Fisik}

Dalam melakukan kerja fisiknya. terdapat proses kontraksi otot yang didukung oleh proses metabolisme oksidasi didalam sel otot. Beban kerja otot tersebut dinyatakan dengan banyaknya konsumsi oksigen dalam liter per menit. Dalam satu liter yang dikonsumsi sama dengan $5 \mathrm{kkal}$ $(20 \mathrm{~J})$ Salah satu indikator dalam mengevaluasi kapasitas kerja fisik adalah kapasitas aerobik maksimal atau maximal physical work capacity (MPWC). Konsumsi maksimum oksigen (VO2 max) menggambarkan kemampuan seseorang dalam memperoleh oksigen. MPWC dapat diketahui dengan adanya kapasitas maksimu jantung dan paruparu dalam mengirimkan oksigen ke otot-otot yang bekerja.Menurut NIOSH dalam Soleman [5] MPWC rata-rata untuk pria sehat sekitar $15 \mathrm{kkal} /$ menit dan wanita $10.5 \mathrm{kkal} / \mathrm{menit}$.

Kapasitas aerobik maksimum dapat ditentukan dengan 2 metode yaitu :

a. Metode maximal test

Pada metode ini responden diminta mengerahkan semua kemampuannya untuk mencapai kapasitas aerobik maksimum seperti penggunaan treadmill. Pada metode ini. akan menghasilkan gejala kelelahan dan tanda-tanda lain seperti mual, pusing, sesak nafas bahkan pingsan.

b. Metode submaximal test

Responden tidak dipaksakan untuk mencapai kondisi maksimum sehingga dampak kelelahan. resiko dan bahayanya lebih rendah.

\section{Pengukuran beban kerja dan konsumsi oksigen}

Pengukuran energi yang dibutuhkan saat bekerja pada umumnya dapat dilakukan dengan pengukuran tidak langsung dengan menghitung jumlah oksigen yang digunakan per satuan waktu. Evaluasi nilai absolute kebutuhan energi setiap individu dengan mengklasifikasikan pekerjaan menurut jenisnya seperti dijelaskan pada tabel 1
Tabel 1 Kebutuhan energi untuk setiap klasifikasi pekerjaan - Kromer dalam Soleman [5]

\begin{tabular}{|l|c|c|l|l|}
\hline \multirow{2}{*}{$\begin{array}{l}\text { Klasifikasi } \\
\text { Pekerjaan }\end{array}$} & \multicolumn{2}{|c|}{ Total energi ekspenditur } & \multirow{2}{\text{Denyutjantung}}{$\begin{array}{c}\text { Konsumsi } \\
\text { (denyut/menit) }\end{array}$} & $\begin{array}{c}\text { oksigen } \\
\text { (//menit) }\end{array}$ \\
\cline { 2 - 3 } (kJ/menit) & (kkal/menit) & $\leq 90$ & $<0.5$ \\
\hline Ringan & $10-20$ & $<2.5$ & $\leq 90$ & $0.5-1.0$ \\
\hline Sedang & $20-30$ & $2.5-5.0$ & $90-110$ & $1.0-1.5$ \\
\hline Berat & $30-40$ & $5.0-7.5$ & $110-130$ & $1.5-2.0$ \\
\hline Sangat Berat & $40-50$ & $7.5-10$ & $130-150$ & $>2.0$ \\
\hline Ekstrim Berat & $50-60$ & $>10$ & $150-170$ & \\
\hline
\end{tabular}

Evaluasi beban kerja dapat juga dianalisa dengan mengukur denyut jantung seperti pada tabel 2.1 Semakin berat kerja fisik seseorang. Maka semakin berat juga kerja jantung yang diindikasikan dengan adanya kenaikan nilai denyut jantung. Pendekatan lain untuk evaluasi beban kerja adalah membandingkan denyut jantung dengan maksimal heart rate (HR maks) yang dimiliki oleh masingmasing pekerja (dewasa). Perhitungan HR maks adalah sebagai berikut :

HR maks $=220$-umur

HR maks $=260-(0.62 \times$ umur $)$ atau

HR maks $=190-0.62 \times($ umur -25$)$

Pengukuran beban kerja fisiologis lainnya adalah dengan menentukan persentase indicator heart rate range (HRR) dengan rumusan sebagai berikut :

$$
H R R(\%)=\frac{100\left(H R_{\text {ker ja }}-H R_{\text {istirahat }}\right.}{H R_{\text {maks }}-H R_{\text {istirahat }}}
$$

Dimana :

$\mathrm{HRR}=$ heart rate range

HR kerja = denyut jantung diukur saat bekerja

HR istirahat $=$ denyut jantung diukur saat istirahat (istirahat selama 20 menit

dengan berbaring)

HR maks = denyut jantung maksimum.

Pekerja yang melakukan aktivitasnya selama 8 jam berturut-turut nilai HRR

rata-rata yang baik adalah tidak lebih dari $33 \%$.

Menurut Soleman [5] ketika suatu pekerjaan dilakukan maka konsumsi oksigen merupakan tolak ukur pengukuran produksi metabolisme energi. Metode evaluasi konsumsi oksigen merupakan metode yang dapat diandalkan dalam proses metabolisme. Menurut Kroemer dkk (1997) ratarata nilai energi. sama dengan $5 \mathrm{kkal} /$ liter oksigen. 
Selain itu juga dengan menggunakan nilai dari normogram Astrand Ryhming dapat juga diprediksi penggunaan VO2. Normogram yang diberikan oleh peneliti ini adalah sebagai berikut:

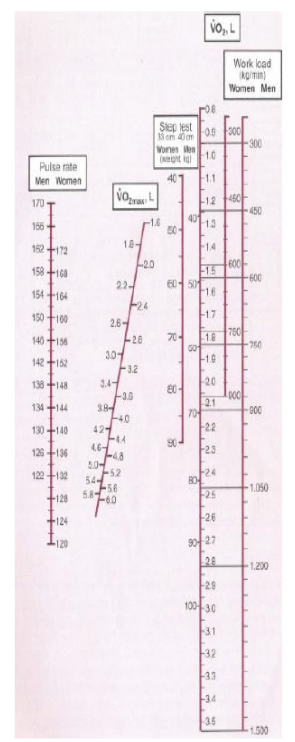

Gambar 4 Normogram Astrand-Ryhming

\section{Uji Statistik}

Terdapat beberapa penguji statistik yang digunakan pada penelitian ini yaitu:

1. Asumsi linieritas

Asumsi linieritas digunakan untuk mengetahui bahwa terdapat hubungan linier antara variable independen dan dependen [6]

2. Asumsi kenormalan

Uji asumsi kenormalan digunakan untuk menguji model regresi variabel-variabelnya memiliki distribusi normal [6]. Pengujian asumsi normalitas error dilakukan secara visual dengan menggunakan histogram dan normal probability plot.

3. Uji independensi Error

Independensi error dapat diuji dengan statistic Durbin- Watson dimana digunakan untuk mengetahui autokorelasi dari variable independen yang akan pada penelitian ini.

4. Uji multikolinearitas antar variable independen Uji ini bertujuan untuk mengetahui ada tidaknya korelasi antar variabel independen [6]. Multikolinearitas antar variable dapat dilihat dari nilai statistic toleransi dan VIF (Variance Inflation Factors). Model dikatakan tidak ada multikolinearitas antar variable jika nilai VIF kurang dari 10 artinya dan nilai toleransi sebuah regresi $>0.10$

5. Interpretasi hasil

Pengujian interpretasi hasil menggunakan metode stepwise. Regresi Stepwise merupakan salah satu metode untuk mengatasi adanya kasus multikolinieritas yaitu suatu kondisi dimana terjadi korelasi yang kuat diantara variabelvariabel independen. Dengan metode ini.akan didapat persaman regresi yang mencakup variable-variabel independen apa saja yang akan mempengaruhi konsumsi VO2.

\section{Hasil Dan Pembahasan}

\section{Populasi Penelitian}

Populasi dalam penelitian ini adalah mahasiswi Teknik Industri Universitas Riau Kepulauan (UNRIKA). Populasi tersebut diambil dari 4 angkatan yaitu angkatan 2013, 2014 dan 2015 dan 2016 Jumlah dari seluruh mahasiswa (pria dan wanita) 4 angkatan tersebut ialah 240 orang. Dari jumlah tersebut hanya sekitar $80 \%$ nya bekerja di galangan kapal dan elektronika dan 20\% lagi adalah bekerja di bidang industri lainnya dan ada yang tidak bekerja (Gambar 7)

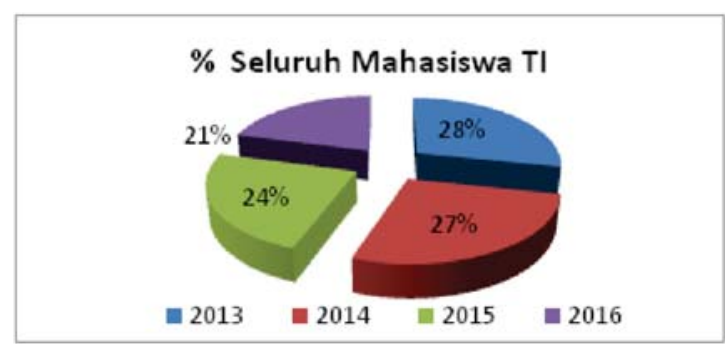

Gambar 5 Persentase seluruh Mahasiswa Teknik Industri Unrika

Dari 240 total mahasiswa Teknik Industri terdapat 29 wanita (mahasiswi). Berikut ini adalah persentase mahasiswi (wanita) Teknik Industri setiap angkatan yaitu: 


\section{\% Mahasiswi TI Tiap Angkatan}

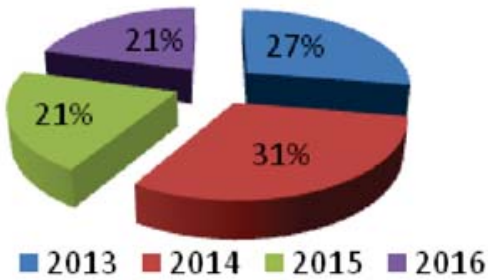

Gambar 6 Persentase Mahasiswi Teknik Industri Unrika

Dari 29 mahasiswi ditemukan sekitar 80\% mahasiswi bekerja dan kebanyakan bekerja di perusahaan elektronika. Berikut adalah persentase mahasiswi yang bekerja (dalam setiap angkatan)

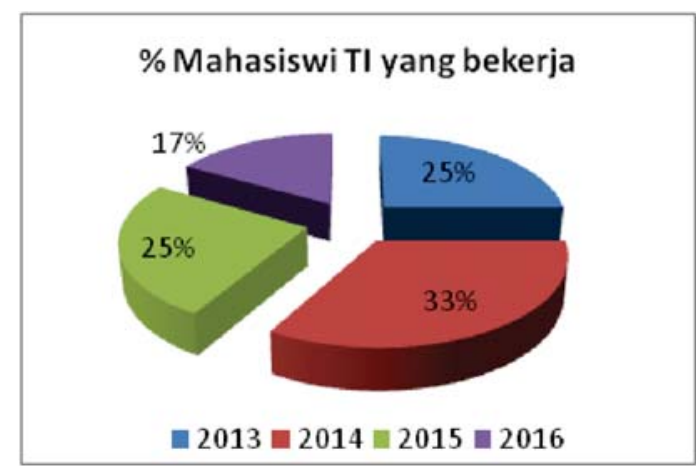

Gambar 7 Persentase Mahasiswi yang bekerja

Dari 24 jumlah mahasiswi Teknik Industri, diambil 19 orang untuk diambil data pengukuran dengan perincian usia sebagai berikut:

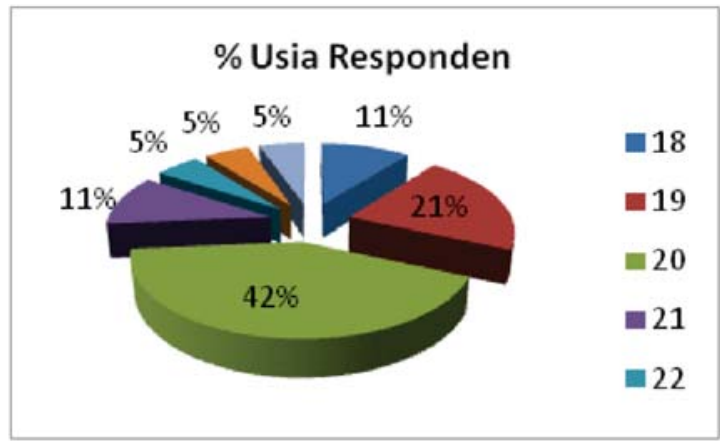

Gambar 8 Persentase usia masing-masing responden

Dalam penelitian ini didapati bahwa data mayoritas yang diambil ialah banyaknya mahasiswi pekerja yang sudah bekerja lebih dari 0-3 tahun di elektronika maupun di perusahaan jasa lainnya. Berikut perincian lama bekerja di seluruh mahasiswi.

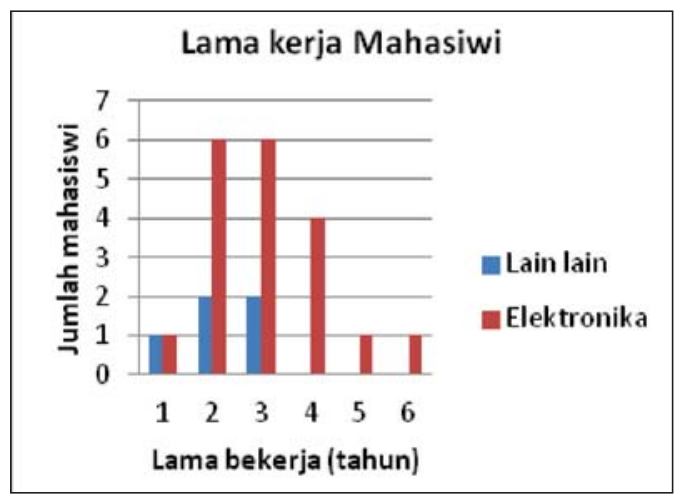

Gambar 9 Lama Kerja Objek Penelitian

\section{Aktivitas Konsumsi Oksigen}

a. Submaximal test dengan mengayuh sepeda ergocycle

Pada aktivitas ini mahasiswi diminta untuk mengayuh sepeda dengan dan tanpa beban denga durasi waktu 2 menit, 4 menit, 6 menit, dan 8 menit sehingga didapatkan denyut jantung per menit.

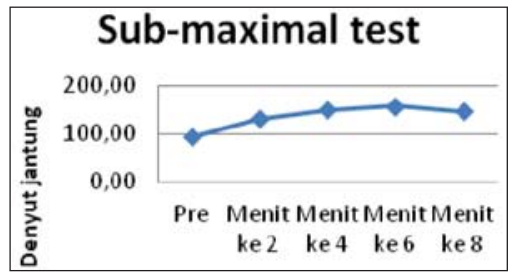

Gambar 10 Denyut nadi setiap dua menit pada kegiatan mengayuh sepeda

Pada kegiatan mengayuh sepeda ini, denyut nadi setelah dua menit mengalami peningkatan sampai pada menit ke-7. Namun pada menit ke-8 kemampuan jantung untuk beraktivitas berkurang sehingga denyut nadi berkurang. Prediksi VO2 menggunakan teori Normogram Astrand-Ryhming dimana dari kegiatan ini ratarata konsumsi VO2 maksimum adalah $2.68 \mathrm{~L} /$ min dan berdasarkan tabel beban kerja maka diklasifikasikan sebagai pekerjaan ekstrim berat.

b. Aktivitas Pengangkatan beban manual (manual material handling)

Kegiatan ini dilakukan dengan mengangkat beban seberat $5 \mathrm{~kg}$ dari meja dan meletakkan 
kembali ke meja yang lain dengan jarak $3 \mathrm{~m}$ serta dilakukan selama 10 menit. Pada pengangkatan benda secara manual menunjukkan bahwa terjadi penurunan nilai denyut jantung pada menit ke 10.

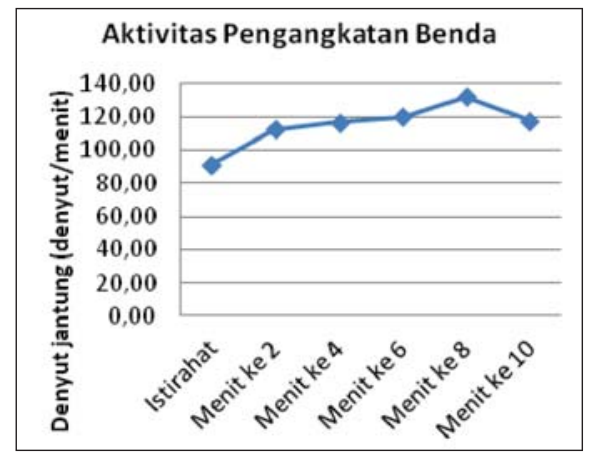

Gambar11 Denyut nadi setiap dua menit pada kegiatan mengangkat benda

Dengan menggunakan gambar Normogram Astrand-Ryhming maka diprediksi penggunaan VO2 max nya pada menit ke sepuluh rata-rata adalah $5.24 \mathrm{~L} / \mathrm{min}$ artinya diklasifikasikan sebagai pekerjaan yang ekstrim.

Hasil Pengujian Statistik

1. Uji linearitas

\begin{tabular}{|ll|l|l|l|l|l|}
\hline Model & & $\begin{array}{l}\text { Sum of } \\
\text { Squares }\end{array}$ & df & $\begin{array}{l}\text { Mean } \\
\text { Square }\end{array}$ & F & Sig. \\
\hline 1 & Regression & 3.699 & 1 & 3.699 & 82.066 & $.000^{\mathrm{a}}$ \\
& $\begin{array}{l}\text { Residual } \\
\text { Total }\end{array}$ & .766 & 17 & .045 & & \\
& 4.465 & 18 & & & \\
\hline 2 & Regression & 3.792 & 2 & 1.896 & 45.097 & $.000^{\mathrm{b}}$ \\
& Residual & .673 & 16 & .042 & & \\
& Total & 4.465 & 18 & & & \\
\hline
\end{tabular}

a. Predictors: (Constant), HR

b. Predictors: (Constant), HR, Tinggi

c. Dependent Variable: VO2_max

Nilai $\mathrm{F}<0.05$,menunjukkan ada hubunganl linier yang signifikan antara variabel dependen dan independen
2. Uji Multikolinearitas

Coefficients $^{\mathrm{a}}$

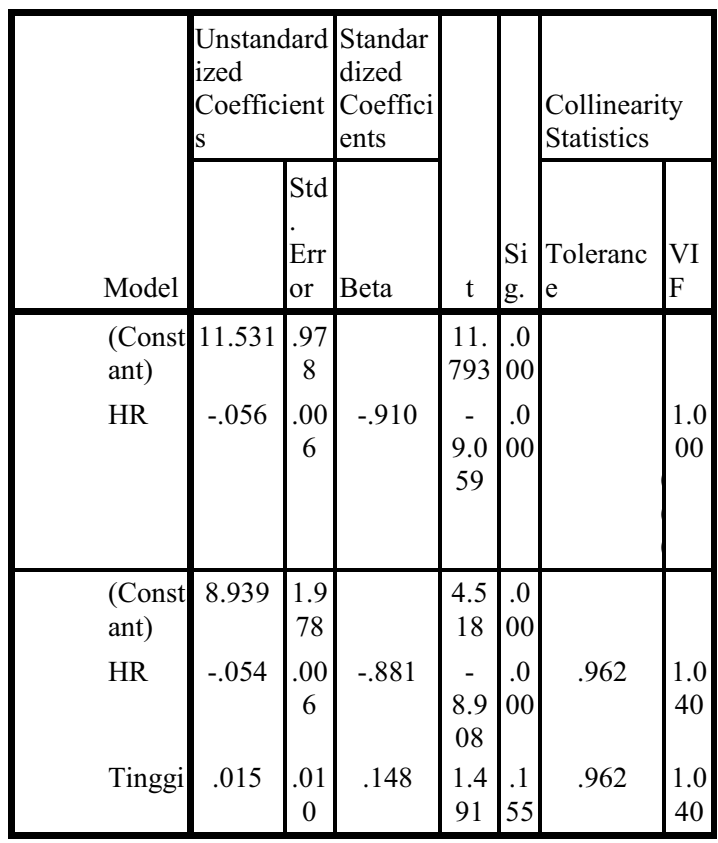

Nilai VIF $<10$ dan toleransi $>0.10$ maka tidak ada asumsi mulikolinearitas antar variabel indipenden

\section{Persamaan $\mathrm{VO} 2$}

Model Summary ${ }^{\mathrm{e}}$

\begin{tabular}{|l|l|l|l|l|l|}
\hline Model & $\mathrm{R}$ & $\begin{array}{l}\mathrm{R} \\
\text { Square }\end{array}$ & $\begin{array}{l}\text { Adjusted R } \mathrm{R} \\
\text { Square }\end{array}$ & $\begin{array}{l}\text { Std. } \\
\text { Error of } \\
\text { the } \\
\text { Estimate }\end{array}$ & $\begin{array}{l}\text { Durbin- } \\
\text { Watson }\end{array}$ \\
\hline 1 & $.910^{\mathrm{a}}$ & .828 & .818 & .21231 & \\
2 & $.922^{\mathrm{b}}$ & .849 & .830 & .20506 & 2.330 \\
\hline
\end{tabular}

a. Predictors: (Constant), HR

b. Predictors: (Constant), HR, Tinggi

c. Dependent Variable: VO2_max 


\begin{tabular}{|c|c|c|c|c|c|c|c|}
\hline \multicolumn{8}{|c|}{ Coefficients ${ }^{\mathrm{a}}$} \\
\hline \multirow[b]{2}{*}{ Model } & \multicolumn{2}{|c|}{$\begin{array}{l}\text { Unstandard } \\
\text { ized } \\
\text { Coefficient } \\
\text { s }\end{array}$} & \multirow{2}{*}{\begin{tabular}{|l} 
Standard \\
ized \\
Coefficie \\
nts \\
Beta \\
\end{tabular}} & \multirow[b]{2}{*}{$\mathrm{t}$} & \multirow[b]{2}{*}{$\begin{array}{l}\mathrm{Si} \\
\mathrm{g} .\end{array}$} & \multicolumn{2}{|c|}{$\begin{array}{l}\text { Collinearity } \\
\text { Statistics }\end{array}$} \\
\hline & B & $\begin{array}{l}\text { Std. } \\
\text { Error }\end{array}$ & & & & $\begin{array}{l}\text { Tolera } \\
\text { nce }\end{array}$ & VIF \\
\hline $\begin{array}{l}1 \text { (Const } \\
\text { ant) }\end{array}$ & $\begin{array}{l}11.5 \\
31\end{array}$ & .978 & & $\begin{array}{l}11.7 \\
93\end{array}$ & $\begin{array}{l}.00 \\
0\end{array}$ & & \\
\hline HR & -.056 & .006 & -.910 & $\begin{array}{l}- \\
9.05 \\
9\end{array}$ & $\begin{array}{l}.00 \\
0\end{array}$ & 1.000 & $\begin{array}{l}1.0 \\
00\end{array}$ \\
\hline $\begin{array}{l}2 \text { (Const } \\
\text { ant) }\end{array}$ & $\begin{array}{l}8.93 \\
9\end{array}$ & 1.978 & & $\begin{array}{l}4.51 \\
8\end{array}$ & $\begin{array}{l}.00 \\
0\end{array}$ & & \\
\hline HR & .054 & .006 & -.881 & $\begin{array}{l}- \\
8.90 \\
8\end{array}$ & $\begin{array}{l}.00 \\
0\end{array}$ & .962 & $\begin{array}{l}1.0 \\
40\end{array}$ \\
\hline Tinggi & .015 & .010 & .148 & $\begin{array}{l}1.49 \\
1\end{array}$ & $\begin{array}{l}.15 \\
5\end{array}$ & .962 & $\begin{array}{l}1.0 \\
40\end{array}$ \\
\hline
\end{tabular}

a. Dependent Variable: VO2_max

\section{Kesimpulan}

Dari hasil dan pembahasan yang dijelaskan diatas maka dapat diambil kesimpulan sebagai berikut :

a. Pada penelitian ini $80 \%$ mahasiswi bekerja di elektronika sedangkan sisanya di bidang lain dengan rata-rata mahasiswi yang bekerja memiliki 0-3 tahun pengalaman bekerja.

b. Terdapat korelasi antara konsumsi VO2 maksimum dengan denyut jantung dan tinggi badan sehingga menghasilkan persamaan VO2 $=-0.054 \mathrm{HR}+0.015$ Tinggi +8.939

\section{Ucapan Terima Kasih}

Peneliti mengucapkan terima kasih kepada Bapak/Ibu dosen serta mahasiswa yang mendukung penelitian ini

\section{DAFTAR PUSTAKA}

[1] Sukawati SY. 2010 Nilai VO2max Mahasiswa Kobe Jepang Lebih Tinggi daripada Mahasiswa Fakultas Kedokteran Universitas Sebelas Maret Surakarta.Skripsi. UNS

[2] Hasibuan, M S.P. 2005. Manajemen Sumber Daya Manusia, Edisi Revisi. Bumi Aksara, Jakarta.

[3] Sinungan, M. 2005. Produktivitas : Apa dan Bagaimana. Bumi Aksara, Jakarta

[4] Astrand, P.O. and Rodahl, K.2003. Textbook of Work Physiology-Physiologocal Bases of Exercise, second edition. McGraw - Hill Book Company, USA

[5] Soleman A. 2009. Kapasitas Aerobik Maksimum dan Persamaan Prediksi Konsumsi Oksigen Pada Perempuan Pekerja Industri.Tesis ITB 2009

[6] Hair, J.F.JR.,Anderson,R.E, Tatham,R.L. \& Black, W.C.1998. Multivariate Data Analysis. Fifth Edition. Prentice Hall, International, Inc

[7] Irdiastadi H. Yassierli.2014.Ergonomi Suatu Pengantar. PT.Remaja Rosdakarya;Bandung

[8] Purnawan AW. Sangtraga HA. 2012. Pengembangan Persamaan VO2 dan Evaluasi HR Max (Studi Awal Pada Pekerja Pria).J@ TI Undip. Vol.VII .No.1. Januari 2012 